\title{
El aborto voluntario en debate. Análisis de la construcción de conciencias públicas en un programa de TV abierta
}

Voluntary abortion in debate. Analysis of the construction of public consciences in an open TV program

Hernán Andrés Caneva hernancaneva@gmail.com

Centro Interdisciplinario de Metodología de las Ciencias Sociales; Instituto de Investigaciones en Humanidades y Ciencias Sociales; Universidad Nacional de La Plata/ Consejo Nacional de Investigaciones Científicas y Técnicas (Argentina)

\section{Resumen}

La lucha por la despenalización y legalización del aborto voluntario en Argentina aborto voluntario está atravesando un momento histórico significativo. Protagonizando la escena 
televisiva durante los meses de enero y febrero de 2018, Intrusos en el espectáculo convocó a diferentes mujeres que se pronunciaron a favor del aborto voluntario. Entonces, resulta significativo estudiar la mediatización del tema en la TV argentina, indagando cómo se construyen conciencias públicas. En este artículo analizaremos el discurso del conductor y examinaremos en profundad el de una de las primeras invitadas al programa.

Palabras clave: Discursos; aborto; televisión; conciencia pública; feminismo.

\section{Abstract}

The struggle for the decriminalization and legalization of voluntary abortion in Argentina aborto voluntario is going through a significant historical moment. Starring the television scene during the months of January and February 2018, Intruders in the show called for different women who spoke in favor of the voluntary abortion. So, it is significant to study the mediatization of the topic in Argentine TV, investigating how public consciousness is built. In this article we will analyze the driver's speech and examine in depth the one of the first guests of the program.

Keywords: Discourses; abortion; televisión; public awareness; feminism.

La lucha por la despenalización y legalización del aborto voluntario en Argentina aborto voluntario está atravesando un momento histórico significativo (1) (2). Desde comienzos de 2018 la demanda por el aborto voluntario ha adquirido protagonismo en el espacio público (las calles, las plazas, las universidades), así como en la agenda de los medios de comunicación, correlativamente con las sesiones de la cámara de diputados y senadores del Congreso de la Nación (3).

Si bien se puede sostener que la demanda por el aborto voluntario se ha construido progresivamente desde 2005, en la arena pública (Cefaï, 2005), en lo que respecta a su mediatización, lo novedoso de la presente coyuntura histórica es la emergencia de un fenómeno comunicacional (protagonizado por la TV abierta y por las redes sociales) (4) a partir del cual se expanden públicamente las principales consignas políticas y argumentos de La Campaña por el derecho al aborto Legal, Seguro y Gratuito (La Campaña) (5). En esta expansión mediática, se elaboró discursivamente el aborto voluntario como un problema 
público, visibilizándose al movimiento de mujeres y los feminismos (6) como legítimos representantes políticos de esta demanda.

Protagonizando la escena televisa durante los meses de enero y febrero, el programa llamado Intrusos en el espectáculo (Intrusos), que desde hace 18 años se transmite ininterrumpidamente en el canal América TV, convocó a diferentes mujeres que se pronunciaron a favor del aborto voluntario. Si bien el debate sobre aborto computa algunos antecedentes en la TV argentina (7), consideramos que ciertas características específicas del fenómeno revistado por Intrusos lo vuelven paradigmático. Por ejemplo, la centralidad otorgada a la temática del aborto voluntario en un programa de TV abierta de elevada audiencia; el respeto por los turnos de habla; el tiempo brindado para desarrollar puntos de vista y los argumentos/explicaciones sobre el tema; el protagonismo de voces feministas a favor del aborto voluntario, representantes de La Campaña.

Asimismo, se puede considerar a Intrusos como uno de los programas disparadores del debate sobre el aborto voluntario en el resto de la TV, lo que se constató en el protagonismo del tema en diferentes canales (de TV abierta y cable) con programas de diferentes formatos y dirigidos a diferentes públicos. Con relación a una problemática social que históricamente representaba una demanda casi exclusiva del movimiento de mujeres y los feminismos (Beluschi, 2014; Brown, 2006, 2008), cabe problematizar la mediatización del tema en la TV argentina, indagando cómo se construye la conciencia pública sobre la despenalización y legalización del aborto voluntario.

En este sentido, es válido plantear que el programa Intrusos se erigió como un actor relevante en la construcción del aborto voluntario como problema público en Argentina (Gusfield, 2014). Con vistas a analizar los principales discursos que se desplegaron en Intrusos, en este artículo abordaremos el discurso de presentación del conductor y examinaremos el de la señorita Bimbo, primera invitada al programa, que desarrolló tres argumentos fundamentales:

1. El carácter "objetivo/real" de la práctica del aborto voluntario

2. La "desigualdad social" que supone la práctica del aborto voluntario en la clandestinidad

3. La "necesidad" de despenalizar y legalizar el aborto voluntario

En tal sentido, recurrimos a una metodología cualitativa e interpretativa que se apoya en el análisis del discurso (Angenot, 1998, 2010; Arnoux, 2006; Robrieux, 1993) y la argumentación (Grize, 2009; Perelman, 1958). Orientados en la sociología de los problemas púbicos y con una mirada de género (gender) (Buttler, 1990, 2010; Castellanos, 2006; Gutiérrez, 2003; 
Fernández, 1993; Scott, 1996, 2011, 2012), proponemos analizar los principales enunciados y argumentos, identificando las elaboraciones retóricas para convencer y persuadir al público. Nuestro corpus está constituido por una selección de fragmentos del programa desgrabados a texto escrito.

\section{Intrusos}

Intrusos es un programa de televisión abierta que desde 2001 hasta la actualidad se transmite ininterrumpidamente por el canal América TV. Desde su aparición hasta la actualidad, el programa ha conservado el formato de un "noticiero de espectáculos", con una escenografía similar a la de los programas informativos, donde la dinámica de la comunicación emula el living de una casa, con un sillón preferencial para el anfitrión (el conductor), un equipo de panelistas sentados alrededor (en su mayoría periodistas de espectáculos) y los invitados. Si bien la temática del programa versa mayormente sobre "chimentos" que involucran a figuras públicas del mundo del espectáculo, también se desarrollan temas de "agenda" que involucran la política, la economía, la cultura y la justicia.

Por otra parte, el programa tiene un elevado rating -considerando su horario de transmisióncon aproximadamente 4.5 puntos promedio, lo que equivale a unas aproximadamente 450000 personas, sólo en Capital Federal y en el gran Buenos Aires (12). Estos datos estimados, representan valores relativos si incluimos en los guarismos a los usuarios de redes sociales, como Tweeter e Instagram, quienes "siguen" los temas del programa e interactúan a través de comentarios, encuestas, retweets, etcétera. En definitiva, Intrusos no es un programa seguido por pequeños públicos, sino un producto televisivo que llega masivamente a los hogares argentinos. La versatilidad y los ajustes de formato del programa se corresponden con su capacidad de absorber los intereses de audiencias amplias y diversas. Se reconoce también que el programa tiene una importante "llegada" a los denominados "sectores populares".

Si bien el formato de Intrusos se ha centrado, durante sus primeros años, en publicitar las intimidades de la farándula, con un estilo periodístico intrusivo o "paparazzi", en los últimos años ha virado al abordaje de temas de interés general, probablemente al calor del éxito televisivo de algunos programas de periodismo político con formato panel que protagonizan la escena de dicho canal (13). A pesar de los rediseños, el programa ha sostenido su continuidad a los largo de los años. 
A partir de la observación de este programa, se puede sostener que una de sus cualidades preponderantes es la capacidad de procesar en "clave sociológica" diferentes acontecimientos que ocurren en el mundo de la farándula, proponiendo miradas concientizadoras que reflexionan sobre la sociedad, la economía, la cultura y la política. Las transformaciones de formato del programa y las mutaciones en los perfiles de las audiencias televisivas se pueden analizar, asimismo, en el marco de los usos de las nuevas tecnologías 2.0, particularmente las redes sociales, las cuales intervienen en la colocación de temas en la agenda mediática e interactúan en tiempo real con los programas.

Podría inferirse que una de las claves del éxito televisivo de Intrusos se debe a la presencia de su conductor, Jorge Rial, un periodista multifacético que ha construido una suerte de "tradición" en la televisión y -particularmente- en el periodismo de espectáculos, a través de una continuidad ininterrumpida en la conducción del programa. Se puede pensar que su contacto cercano con las audiencias dota a su opinión de cierta credibilidad (14), siendo su propuesta de "debatir el aborto voluntario", un fenómeno paradigmático que interpeló a diversos sectores de la sociedad argentina.

\section{"Quiero hacer el debate de verdad". El discurso de Jorge Rial}

La apertura del programa del 2 de febrero de 2018 representaría una efeméride simbólicamente relevante en la lucha por el aborto voluntario. En aquel día, Jorge Rial apareció en la pantalla portando en el brazo un pañuelo verde para manifestar su adhesión a La Campaña.

Entonces, pronunciaría:

me alegra de verdad que sea Intrusos quien dio este puntapié inicial; ojalá que se desborde en toda la televisión y podamos de verdad, y de manera adulta, empezar a hablar de esto que ya está, que tiene que ver con el feminismo; y el próximo paso va a ser el tema del aborto legal, ¿eh? Del aborto gratuito. Es lo que se viene (Jorge Rial, programa del 2 de febrero de 2018).

Como se observa en esta cita, el conductor planteó el vínculo entre el debate por el aborto voluntario y el sentido político del feminismo. Que se atribuyera tal legitimación al feminismo en tanto que ideología/pensamiento político capaz de protagonizar el debate del aborto voluntario 
en un programa de TV abierta argentina representó un hecho inédito, cuya influencia en la posterior mediatización del tema así como en la construcción de una conciencia pública necesitamos analizar.

Pero el rol de Intrusos en la publicitación de la demanda por el aborto voluntario fue todavía más allá de la manifestación de una postura adherente a La Campaña por parte del conductor. Porque en la apertura de aquel programa del 2 de febrero, Rial plantaría la necesidad de llamar a voces autorizadas para hacer -en palabras suyas- un debate "de verdad" sobre el aborto voluntario. Reconociendo que su opinión en tanto que figura pública podría influir tendenciosamente sobre la audiencia y que los panelistas de su programa se pronunciarían guiados por creencias y opiniones personales, el conductor sostuvo que ofrecer un debate "de verdad" suponía convocar a aquellas voces que tuvieran los conocimientos, trayectorias profesionales, personales y políticas legítimas/válidas para pronunciarse sobre el tema ante la audiencia.

En este punto, podríamos preguntar qué criterios determinaron la experticia para debatir sobre el aborto voluntario. Se puede pensar que en aquel llamamiento a dar un debate "de verdad", Rial estableció ciertas "reglas" a partir de las que se debatiría la problemática. Si bien en su discurso de apertura argumentó que quería "hacer el debate con todos, los que están a favor y los que están en contra", cabe señalar que las voces que circularon en Intrusos durante ese mes fueron mayormente las de mujeres feministas con un posicionamiento marcadamente "a favor" del aborto voluntario.

A partir de la observación de diversos programas emitidos durante ese período, podemos hipostasiar que en Intrusos, más que un debate, se desarrolló una campaña de publicitación a favor del aborto voluntario. En esta dirección, sostenemos que Intrusos se erigió como un actor relevante en la publicitación del aborto voluntario, así como en la construcción de una conciencia pública adherente al discurso de La Campaña. Las huellas que abonan este supuesto podrían rastrearse en el discurso de apertura del conductor del programa, quien argumentó que el aborto es un problema "objetivo", "real", "serio", "urgente", "razonable", que excede las creencias individuales, significando un problema para todas las mujeres.

En su discurso de apertura, el conductor designó, además, a los "responsables políticos" de la problemática social del aborto voluntario: "Ios políticos", "Ios funcionarios". También exigió una solución inminente y concreta al problema: la sanción de una ley.

...más allá de la gente que nos mira, yo le digo a los políticos, y muchos ayer me llamaron y aplaudían esta decisión de tocar el tema y yo les decía: está bien que aplaudan y todo, pero 
acompañen el aplaudir con laburo. Lleven este tema al Congreso y debátanlo, y quiero decir que quien perdió una gran oportunidad de tocar este tema en algún momento, fue casualmente, una mujer, que fue Cristina Kirchner, que nunca quiso hablar de este tema; cuando tenía la mayoría y todo, nunca quiso hablar de este tema. Un gran retroceso, hay que decirlo también, y sé que muchas están dolidas por eso (...) Pero bueno, pero es así; lo que le digo a los políticos es 'muchachos, aplaudan todo lo que quieran, vean Intrusos, les agradecemos mucho, pero lleven estas leyes'. Vamos a debatirlo, hagamos un debate con todos, los que están a favor, los que están en contra. Saquemos nuestras conclusiones (Jorge Rial, programa del 2 de febrero de 2018).

En este segmento se puede observar la interpelación a "los políticos" como responsables de establecer soluciones concretas a la problemática social del aborto voluntario. En clave de género (gender), se infiere que Rial, al hablarles a los "muchachos" para referirse a la clase política, opera una generalización mediante la cual se define la política como un ámbito mayormente masculino o bien que naturaliza que las funcionarias mujeres tienen una postura a favor del aborto voluntario. Pero, además, se puede reconocer una auto-representación sobre la función diferencial de los medios de comunicación y de la política. El conductor da a entender que la TV es un medio cuya función es promover la discusión pública y concientizar a la ciudadanía, pero no es el lugar donde efectivamente se producen las transformaciones que la sociedad requiere (como es el caso del aborto voluntario). Ese lugar es el Congreso de la Nación, el Estado y sus instituciones.

\section{“Las mujeres abortan”. El discurso de la señorita Bimbo}

Es frecuente observar en los programas de TV, a "especialistas" o "expertos" que se pronuncian sobre diferentes temas de agenda pública, mediante una retórica que busca argumentar con "objetividad" las problemáticas sociales. Asimismo, los especialistas, quienes frecuentemente hablan como representantes legítimos de los problemas públicos, suelen utilizar una retórica del "como sí" (como si ellos y la audiencia pudieran ubicarse en el lugar de las víctimas), con vistas a promover la identificación del público (15).

Estas y otras formas de la persuasión, las observamos en diferentes emisiones de Intrusos, en las que las invitadas se pronunciaron sobre el aborto voluntario. En este caso, cabe plantear ciertas particularidades de las "expertas" que se pronunciaron en calidad de "representantes" del problema público. Con vistas a mostrar un caso paradigmático, proponemos analizar el 
discurso de la primera invitada al debate, la comediante/comunicadora Virginia Godoy, mejor conocida como señorita Bimbo (16).

Cabe señalar que la presentación de Bimbo en Intrusos no fue en condición de "experta" o "profesional" en la materia, sino más bien en tanto que "representante legítima" de La Campaña. La "verosimilitud" o la "credibilidad" de su exposición en parte se justifican en su propio ethos, es decir, en su historia de vida. Bimbo representa una mujer que toma conciencia de las estigmatizaciones y las violencias padecidas en los medios de comunicación (por ser mujer, por no tener el cuerpo "ideal", etcétera) y que asume un compromiso militante con las luchas del movimiento de mujeres y los feminismos.

Bimbo también es una figura pública dentro mundo de los medios, las redes sociales y el espectáculo. Quizás por ello, y por su propia experiencia biográfica, su exposición en el debate partió de problema de los acosos en el mundo del espectáculo como tema "disparador" (17):

(...) yo aceptaba el 'booling' televisivo porque nadie nace feminista, ni compra que lo personal es político (...) son exponentes (los maltratadores) de algo que está ahí (...) Pettinato (un conductor de TV) no es sólo un loco, que sale de un arbusto y viola; es un señor respetable, que ganó mucho dinero y que funciona en sociedad; pero que tiene esas ideas, como tantos otros, en la cabeza, y además tiene el poder para poder decirlo, comentarlo y tratarte así (...) para muchas generaciones de 30-40 años, parte de esa irreverencia (en referencia al estilo de Pettinato) es el maltrato (...) reírse de los débiles (...) es una sociedad que a todo lo diferente lo maltrata (...) es lo mismo que está en la tele (...) pero nos vamos despertando todos, porque lo natural ya no está bien (...) (Virginia Godoy, programa del 2 de febrero de 2018).

En su exposición, Bimbo se refirió al rol del feminismo como una expresión política que concientiza a la sociedad, que contiene y empodera a las mujeres. Aunque sostuvo que no asistió al programa para hablar en nombre de "el feminismo", señaló la importancia de que se visibilice la voz y la lucha de las mujeres en los medios de comunicación, en el espacio público y en las redes sociales. En este sentido, argumento que aceptaba asistir al programa porque, en una coyuntura histórica de retroceso para los derechos de las mujeres, era necesario "ocupar" cada espacio comunicacional que se abriera. Asimismo, Bimbo argumentó que se debía aprovechar la posibilidad de comunicar la demanda por el aborto voluntario a un público "diferente", al que caracterizó como "las pibas que miran Intrusos". Es interesante pensar, en este punto, la presencia de cierta auto-representación de la TV como un medio de comunicación donde lo anecdótico o lo auto-biográfico no es suficiente para legitimar la 
palabra. Es decir, que Bimbo no fue a hablar como Bimbo sino además como representante de razones públicas que la exceden y que asimismo, es necesario divulgar a la sociedad.

Con relación al feminismo, argumentó que "ser feminista" no se subsume a luchar por la igualdad de derechos, ni tampoco a sentir empatía con los casos más "extremos" de violencia de género. Por el contrario, argumentó que el feminismo es un comportamiento, una toma de conciencia, que implica interrogarse qué es ser varón y qué es ser mujer, es decir, cuestionar los roles que ocupan mujeres y varones en la estructura social patriarcal. Argumentó que "ir hasta el fondo", "cuestionarlo todo" (la propia identidad, la normalidad) es una de las razones del rechazo, la aversión o el temor que produce el feminismo en parte de la sociedad. Sostuvo que esa mirada sesgada y equívoca sobre el feminismo es construida por diversos medios de comunicación, que lo caracterizan como un "fanatismo radicalizado" de un grupo de mujeres desquiciadas que violentan el espacio público para perseguir demandas que no corresponden a los intereses de la comunidad.

Para Bimbo, la conciencia feminista no es sólo una cuestión de mujeres y/o varones, sino que implica una ruptura generacional. En palabras suyas, "las nuevas generaciones ya saben que no puede ser así". Argumentó que las generaciones de entre veinte o treinta años tomaron conciencia de que lo que antes era "normal" ahora "ya no está bien". Bimbo se refirió a la observación de cierta maduración social y política en la conciencia sobre la dominación patriarcal, que le debe al feminismo una cuota significativa. Entonces, una de las labores políticas del feminismo fue -durante estos últimos años- provocar la intolerancia hacia ciertas prácticas que antes se consideraban normales, así como promover debates sobre temas que otrora estaban invisibilizados o naturalizados. Para Bimbo, que Intrusos proponga debatir el aborto voluntario no es "magia" sino parte de un cambio de mentalidad promovido por el feminismo.

Sin embargo, el discurso de Bimbo asumió un tono polémico (Amossy, 2015) al denunciar del silenciamiento y la invisibilización del tema del aborto voluntario en la TV (18). En esta dirección, argumentó que:

(...) en televisión el aborto no existe (...) no abortan ni en ficciones las mujeres; lo máximo que te pasa es 'te tiran por la escalera y perdiste a un bebé' (...) no pasa, tampoco en televisión. Bueno, porque hay una pauta (publicitaria) de pañales, en el corte (Virginia Godoy, programa del 2 de febrero de 2018). 
A pesar del soslayamiento del aborto en este medio, argumentó que los consumidores de TV no son estúpidos o pasivos, ya que actualmente, las redes sociales tienen la capacidad de anticiparse en la producción y circulación de la información. De manera que la TV, debido a la presión pública ejercida por estos nuevos dispositivos, eventualmente se encuentra obligada a incluir temas/problemas/acontecimientos que son de interés público; para Bimbo, la TV no puede establecer las agendas o los contenidos que consumen sus audiencias como lo hiciera históricamente (19).

Pero, ¿por qué el aborto ha estado históricamente poco presente en la agenda de los medios de comunicación? Bimbo argumentó, en este sentido, que su ausencia es producto de la ignorancia (intencional o no) de que el aborto voluntario constituye un problema de salud pública:

(...) todavía se piensa que el tema del aborto tiene que ver con la moral, con las opiniones, con la religión, y es una cuestión de salud pública (Virginia Godoy, programa del 2 de febrero de 2018).

(...) es respetable lo que cada una piense y sienta, pero se producen alrededor de 500000 abortos clandestinos por año, 500000.Las mujeres abortan, abortarán; el punto es cómo lo hacen. Con 20 lucas o como sea, donde sea (Virginia Godoy, programa del 2 de febrero de 2018).

(...), es la primer causa de muerte de mujeres gestantes; mientras nosotras debatimos se está muriendo una (Virginia Godoy, programa del 2 de febrero de 2018).

La retórica de Bimbo desnuda su aspecto persuasivo y dramático en el carácter de "urgencia" que deslizan enunciados como: "500000 abortos clandestinos por año, 500000" o "mientras nosotras debatimos, se está muriendo una mujer". Se puede inferir que "ponerse de acuerdo" no implica arribar a un consenso entre las creencias y opiniones personales, sino asumir la existencia de una realidad objetiva.

Probablemente por esta razón, Bimbo sostuvo que todas las creencias son respetables, pero argumentó que centrarse en las creencias u opiniones personales implica "diluir" el debate, es decir, correr la mirada sobre el problema público del aborto voluntario así como de las transformaciones necesarias para su solución. En este sentido, explicó con énfasis que las creencias deben separarse del derecho: 
(...) se tiene miedo porque tenemos un Estado unido a la Iglesia, porque sabemos la postura de la Iglesia, y donde se meten cuestiones personales que no tienen que ver con lo que pasa. Hay católicas por el derecho a decidir, les cuento a las que están del otro lado (...) y dicen 'yo soy católica, yo (...)' bueno, charlen con ellas, vean que hay otras maneras en que no interfiera lo que crees con la realidad, que mueren mujeres (Virginia Godoy, programa del 2 de febrero de 2018).

En relación con lo anterior, sostuvo que el argumento recurrente en los discursos anti-aborto, (dar al bebé en adopción) es el "mejor caso" para comprender qué significa el aborto voluntario. Cabe recordar que Bimbo es hija de padres adoptivos, un dato biográfico que le permitió pronunciarse con cierta legitimidad sobre el tema. A través de una operación de generalización, argumentó que detrás de una historia de adopción existe una historia de abandono, es decir, de una mujer que por diversas razones no quiso (o no pudo) ser madre. Explicó que el sistema de adopción en Argentina es ineficaz. Sin embargo, manifestó que no se trata de discutir si el sistema es eficaz o no. La cuestión es dejar en claro que las mujeres no abortan bebés sino embriones:

(...) (en) la adopción hablamos de bebés, y cuando hablamos de aborto hablamos de un embrión (...) que ahí está la ciencia; y lo que cada uno piensa es su opinión y se la respeta (...) pero abortan las mujeres, eso es lo que tenemos que entender, que mientras hablamos, eso pasa. Entonces, si le damos la espalda a lo que pasa, van a seguir muriendo las que no puedan pagarlo. Es muy simple. Todos conocemos mujeres que abortaron (el panel de Intrusos asiente); y la que pudo, lo pagó (Virginia Godoy, programa del 2 de febrero de 2018).

Posteriormente, la invitada mencionó el proyecto de despenalización y legalización del aborto voluntario de La Campaña, planteándolo como la solución a esta problemática social:

(...) hay un proyecto, la ley hace un montón de años que está; la campaña hace un montón de años (...) donde se legalizó el aborto bajó la tasa de muertes; no es que vamos a ir todas como locas a abortar; es que las que lo pueden pagar no se van a morir (Virginia Godoy, programa del 2 de febrero de 2018).

Por otra parte, Bimbo introdujo una consigna fundamental de La Campaña: las mujeres tienen derecho a decidir sobre sus propios cuerpos-vidas: 
nadie quiere abortar, o sí (...) pero bueno, también esto de cargar que es una experiencia traumática. Para mí es más traumático llevar un embarazo -no deseado- a término, es una atrocidad (...) decir que hay cosas que nos pasan a todas, que sentimos todas (...) hay cosas que tenemos en común (Virginia Godoy, programa del 2 de febrero de 2018).

Resulta pertinente destacar que el argumento de Bimbo sobre la "deseabilidad" del aborto voluntario confrontó con el que Rial (y el panel de Intrusos) formularan en la apertura del programa. Rial y el panel dieron por sentado que ninguna mujer quiere/desea abortar. Bimbo desmintió este sentido común al formular el enunciado "o si". También, al definir como una atrocidad que una mujer continúe con un embarazo no deseado. En relación al argumento, frecuentemente utilizando por grupos pro-vida, sobre el "trauma" o "síndrome post-aborto", la invitada explicó que puede ser tan traumático llevar adelante un embarazo no deseado como interrumpirlo.

Finalmente, Bimbo cerró su intervención planteando una reflexión sobre la importancia de visibilizar la voz de las mujeres en el espacio público. Convocó a las mujeres a participar de las movilizaciones sociales venideras y deslizó de manera persuasiva una recomendación para el público: "no le tengan miedo al feminismo, que queremos el bien de todos y todas".

\section{Reflexiones finales}

A partir de lo desarrollado en este artículo, pretendemos abrir algunos temas a debate. ¿Qué conciencias públicas sobre el aborto voluntario se construyen en la TV? ¿Qué argumentos 0 razones públicas se ponderan? (Habermas, 1999) ¿Cuáles quedan afuera del debate? ¿Qué aspectos del debate deberían profundizarse para ampliar una conciencia pública emancipatoria en términos de género?

El caso de Intrusos fue paradigmático en diferentes sentidos. Como pudimos observar, en el discurso de Bimbo, su calidad de representante de La Campaña (y del feminismo) fue reconocida en el programa como un rasgo positivo. Ahora bien, su intervención pública apuntó a presentar estratégicamente los nodos más contundentes de la formulación del problema público tal como lo formula el discurso de La Campaña. Otros temas, fundamentales para el feminismo, como es el derecho a la autonomía de las mujeres sobre sus propios cuerpos y el derecho a una sexualidad libre, no tuvieron la misma consistencia que el argumento "las mujeres abortan, muchas se mueren". 
Quizás sea inocente, absurdo o un planteo de escritorio, sugerir que estas discusiones pudieran haber tenido mayor protagonismo en la voz de Bimbo, puesto que la estrategia discursiva apuntó a construir consensos frente la ciudadanía con vistas sumar adherentes a la legalización del aborto voluntario. Así lo demuestra la recurrencia del argumento del aborto voluntario como problema de salud pública y la insistencia en el problema de las muestres de mujeres gestantes. Solamente en una breve mención, Bimbo planteó que las mujeres pueden querer/desear abortar. Sin embargo, la cosmovisión predominante en el programa dio por sentado que no existe deseabilidad alguna en la práctica del aborto voluntario ("ninguna mujer quiere abortar").

Resulta claro que, en la construcción del aborto voluntario como problema público, tanto Rial como Bimbo hicieron hincapié en el desarrollo de razones públicas (Busdygan, 2009; 2018) (como por ejemplo, el derecho a la salud) con vistas a convencer y persuadir a un público amplio y diverso, probablemente ajeno al feminismo y a las consignas de La Campaña. Pero, ¿por qué no profundizar la discusión sobre los aspectos más neurálgicos y polémicos del debate, sobre los que el feminismo viene construyendo desde hace décadas, argumentos consistentes política y académicamente?

Si las luchas por el reconocimiento (Honneth, 1981, 1992, 1997, 2009 a y b) se desarrollan de manera progresiva, parece que, en el despliegue del debate por el aborto voluntario en Intrusos, la estrategia discusiva legitimó al feminismo como expresión política, pero evitó interpelar de manera polémica las creencias y las opiniones potencialmente más "conservadoras" de la audiencia. Porque, según se planteó el problema público, podemos como ciudadanos- estar de acuerdo con la legalización del aborto voluntario, pero al mismo tiempo sostener la opinión personal o la creencia que el aborto voluntario constituye un drama, un trauma, un pecado o una aberración cometida por las mujeres. ¿Qué problemas plantea la continuidad de estos juicios de valor para la autonomía y la emancipación de las mujeres, es decir, para la lucha contra el patriarcado?

Por esta razón, nos interesa continuar pensando si, en la construcción de la opinión pública (Petracci, 2007) a favor del aborto voluntario, se puede sostener la separación entre las "opiniones y creencias personales" y las "razones públicas". Evidentemente, tal separación parece ser un horizonte posible, y probablemente, a partir de las consistentes razones públicas hasta el momento planteadas por La Campaña, se pueda obtener próximamente la ley. Sin embargo, la batalla cultural por el reconocimiento de las mujeres en tanto que sujetos sociales y políticos libres para desear, proyectar y decidir sobre sus cuerpos y vidas, parece todavía combatir contra los blancos de una moral conservadora todavía estimulada por las 
cosmovisiones católicas. Consideramos que esta batalla cultural, anti-patriarcal en lo que refiere a la impugnación del orden social, y feminista en lo que refiere a la construcción de un orden social alternativo, requiere de una deconstrucción de los imaginarios sociales anquilosados y de las prácticas generizadas, que modelan los comportamientos de varones y mujeres en el ámbito público y privado, para lo cual será imprescindible -en los tiempos venideros- sostener la lucha en las escuelas, las universidades, los hogares así como en los medios de comunicación y en el espacio público digital.

\section{Notas}

(1) Este trabajo se enmarca en nuestro proyecto de tesis doctoral titulado "El aborto en Argentina. Análisis crítico de discursos en dos organizaciones (2014-2016)" dirigido por las Dras. Elvira Narvaja de Arnoux y Silvana Sciortino, bajo la supervisión y colaboración de la Dra. Susana Ortale (codirectora de la beca de finalización de doctorado de Conicet, 2017-2019)

(2) Sobre este tema se puede consultar, Bergallo y Michel (2006), Checa (2006), Zamberlin (2007).

(3) El 1 de marzo de 2018 se abren las sesiones del parlamento y el presidente Muricio Macri convoca públicamente a debatir el tema; el 6 de marzo de 2018 se presenta por séptima vez el proyecto IVE; el 10 de abril de 2018 se inicia el debate parlamentario sobre el aborto en la Cámara de Diputados de la Nación.

(4) Para pensar la cuestión de las nuevas tecnologías de la comunicación, nos apoyamos en el concepto de espacio público digital de Cheresky (2015), en los aportes de la etnografía virtual (Hine, 2004) para pensar los usos de las redes sociales, en los aportes de Ferraudi Curto y otros (2017) para pensar la subjetivación política en Facebook y en el trabajo de López y Ciuffoli (2014) para caracterizar esa plataforma digital en la Argentina.

(5) La Campaña una organización multisectorial constituida en 2005. Articula un conjunto de demandas de grupos y organizaciones que forman parte del movimiento amplio de mujeres en Argentina, orientadas a la despenalización y legalización del aborto. Entre sus principales consignas, se define a la interrupción del embarazo como una decisión personal y un derecho de las mujeres sobre sus propios cuerpos. La demanda por la autonomía sexual y reproductiva supone -para esta organización- una transformación de los mandatos socioculturales y de las normativas institucionales que la obstaculizan. Uno de sus principales argumentos en pos de la despenalización y legalización del aborto se apoya en el señalamiento del elevado índice de mujeres que mueren debido a la práctica del aborto voluntario en condiciones inseguras. Se advierte que -en condiciones de clandestinidad- la oferta de servicios de atención es de variada y dudosa confiabilidad, lo cual aumenta el riesgo para la salud y la vida de las mujeres de sectores pobres, quienes se someten a prácticas inseguras (Zamberlin, 2007).

(6) Usamos la expresión "el feminismo" porque así fue mencionada en la TV.

(7) Por ejemplo, en julio de 2011, un programa de TV abierta transmitido por Canal 7 (la TV Pública) llamado En debate, conducido por el periodista Adrián Paenza, propuso un debate sobre el aborto.

(8) Joseph Gusfield (2014), referente de la "sociología de los problemas públicos", analiza cómo se construyó, en la sociedad norteamericana, una "conciencia pública" en relación al problema de las muertes por accidentes de tránsito. Por eso, Gusfield se pregunta por qué la conciencia pública ponderaba el argumento que responsabilizaba 
causalmente al conductor alcoholizado en lugar del estado de las carreteras o las fallas en la fabricación de los automóviles.

(9) Este tema viene siendo investigado tanto en el discurso periodístico como en la arena parlamentaria y en los discursos de organizaciones sociales y políticas que protagonizan la arena pública (Brown, op.cit, 2008; Caneva, 2012, 2014 a, 2014 b y 2015; Rocha y Otros, 2008). En los últimos años, la utilización que La Campaña y Pro-vida hacen de los significantes "vida", "muerte" y "derecho" (y "mujeres", entre otros) en la construcción de argumentos a favor o en contra del aborto voluntario, ejemplifica la dinámica de una confrontación entre cosmovisiones contrapuestas e irreconciliables. Se sostiene que no existe una conciencia pública más o menos unificada sobre el aborto voluntario sino una audiencia a la que se intenta "concientizar" en diferentes direcciones político-ideológicas.

(10) Importa señalar aquí los aportes del trabajo de Gusfield (2014) ya que nos propone observar quiénes son los actores que hablan en escenarios públicos como la TV, cuáles son las cosmovisiones políticas e ideológicas que subyacen a sus discursos, cuáles son sus intereses, qué argumentos utilizan, cómo los construyen, cómo se definen a sí mismos, cuáles son las credenciales que los "acreditan" como interlocutores válidos, cuál es su relación política, profesional y auto-biográfica con la problemática sobre la cual se refieren y a qué público/s intentan convencer y persuadir.

(11) Para pensar este problema, nos apoyamos en el concepto de "coacción argumentativa" de Chateaureynaud (2005).

(12) Información consultada en https://bit.ly/2RuEh68

(13) Nos referimos específicamente al programa Intratables conducido por Santiago Del Moro, y al programa Animales Sueltos, conducido por Alejandro Fantino, que se emiten en horario nocturno.

(14) La "credibilidad" la pensamos como la "confianza" que generan en las audiencias algunas figuras televisas a través de su continuidad en un medio donde los protagonistas aparecen y desaparecen.

(15) Se puede sostener que el uso de datos estadísticos como la persuasión a o partir "ponerse en el lugar del otro" constituyen mecanismos de prueba que legitiman una "buena" argumentación de los problemas públicos en la TV. A su vez, es necesario observar el uso retórico de las cifras, ya que aunque las estadísticas se exhiben como si "hablaran por sí solas", reflejan una situación angustiante-injusta-dramática y urgente que debe ser solucionada

(16) Se trata de una figura pública que en la actualidad se destaca por su labor teatral y la participación en el programa radial Furia Bebé, que se transmite por Futurock de 16 a 18 horas. Su voz es conocida por la audiencia de la radio, la TV y las redes sociales. El estilo de las alocuciones públicas de la señorita Bimbo polemiza pero busca "empatizar" con el público, ya que en su ethos se pone a sí misma como ejemplo. A partir de la "denuncia" de situaciones que considera injustas, Bimbo utiliza el humor para desnaturalizar lo que el sentido común asume como "normal".

(17) En este sentido, la invitada puso como ejemplo su experiencia personal, cuando trabajaba con el conductor Roberto Pettinato en un programa de TV. Pero, con relación a su experiencia personal, Bimbo argumentó que los casos particulares deben entenderse en relación a una coyuntura o situación que experimentan todas las mujeres.

(18) En el análisis de nuestro corpus, observamos que una de las características argumentativas y retóricas de las alocuciones de los invitados a Intrusos (así como del conductor y de los panelistas) es la auto-reflexión sobre el medio televisivo.

(19) "(...) creo que se menosprecia mucho al televidente, y el televidente de televisión es distinto a la persona que consume contenidos en Internet o pagándolo -digamos-; se le habla a 'doña rosa'; hay que avisar que murió 'doña rosa', y que también el marido la maltrataba; entonces al espectador se lo trata como si fuera un idiota, sobre todo porque estaba pasando todo esto en redes y en el mundo antes que llagara acá (la televisión)" (Virginia Godoy, programa del 2 de febrero de 2018). 


\section{Bibliografía}

Angenot, M. (1998). Interdiscursividades. De hegemonías y disidencias (Traducido por María Teresa Dalmasso). Córdoba: Editorial Universidad Nacional de Córdoba.

Angenot, M. (2010). El discurso social. Los límites históricos de lo pensable y lo decible. Buenos Aires: Siglo Veintiuno.

Amossy, R. (2015). Por una retórica del dissensus: las funciones de la polémica". Artículo inédito. Recuperado de https://comycult.files.wordpress.com/2018/04/amossy-ruth-poruna-retc3b3rica-del-dissensus.pdf

Arnoux, E. (2006). Análisis del discurso. Modos de abordar materiales de archivo. Buenos Aires: Santiago Arcos.

Beluschi, M. (2014). Historia de una desobediencia: aborto y feminismo. Ciudad Autónoma de Buenos Aires: Capital Intelectual.

Bergallo, P. y Ramón Michel, A. (2009). El aborto no punible en el derecho argentino. Despenalizacion.org.ar, 9. Recuperado de https://bit.ly/2RDce1k

Brown, J. (2006). Entre el silencio y el escándalo. El aborto como asunto de debate político en la Argentina. Seminario Internacional Fazendo Gênero 7, Gênero y preconceptos, Universidad de Santa Catarina, Florianópolis. Recuperado de https://bit.ly/2PFKmaP

Brown, J. (2008). La cuestión del aborto en Argentina. Una mirada a partir de la prensa periódica. Question. Revista especializada en periodismo y comunicación, 1(20). Recuperado de https://perio.unlp.edu.ar/ojs/index.php/question/article/view/688

Busdygan, D. (2009). Identidad, democracia y razón pública. Los grupos identitarios en la discusión democrática. Actas de las II Jornadas de Filosofía política: Convivencia democrática, Universidad Nacional del Sur, Bahía Blanca, 5.

Busdygan, D. (2018). Aborto. Aspectos normativos, jurídicos y discursivos. Bs. As.: Edit. Biblos.

Caneva, H. (2012). Representaciones sobre el aborto. Estudio de jóvenes escolarizados de sectores pobres de la ciudad de La Plata. (Tesis de grado). Licenciatura en Sociología, Universidad Nacional de La Plata, La Plata. Recuperado de https://bit.ly/2BqbBRx

Caneva, H. (2014a). Voces y silencios. Aborto inseguro y desigualdad en los discursos de distintos organismos. Ponencia Presentada en el XI CAAS, Congreso Argentino de Antropología Social, Rosario. 
Caneva, H. (2014b). Aborto no punible en Argentina: análisis sobre los argumentos sostenidos por miembros de los sistemas de salud y justicia. VIII Jornadas de Sociología de la UNLP, Ensenada. Recuperado de https://bit.ly/2CfNAOP

Caneva, H. (julio de 2015). Ingeniería de la condena. Argumentos sobre el aborto sostenidos por organizaciones Pro-Vida en Argentina. XI Jornadas de Sociología de la Universidad de Buenos Aires, Buenos Aires. Recuperado de http://jornadasdesociologia2015.sociales.uba.ar

Cefaï, D. (2005). Arène publique. Un concept pragmatiste de sphere publique (Traducción Acevedo, Mariela). Francia: Éditions de l'Aube.

Chateauraynaud, F. (2005). La coacción argumentativa. Las formas de argumentación en los marcos deliberativos y las potencialidades de expresión política (traducción de Geraldine Kerneur Brucher). Recuperado de https://bit.ly/2Enes0S

Checa, S. (2006). Realidades y coyunturas del aborto. Entre el derecho y la necesidad. Buenos Aires, Argentina: Editorial Paidós.

Cheresky, I. (2015). El espacio público digital. En El nuevo rostro de la democracia. Buenos Aires: Fondo de cultura económica.

Ferraudi Curto, C; Pinedo, J. y Welschinger, N. (2017). Resistiendo con Aguante. Prácticas de subjetivación política en Facebook como plataforma de militancia. Prácticas de oficio, 1(19).

Grize, J. B. (2009). El punto de vista de la lógica natural: Demostrar, probar, argumentar. En Dury, M. y Moirand, S. La argumentación hoy. Encuentro entre perspectivas teóricas. Barcelona, España: Montesinos Ensayo.

Gutiérrez, M. A. (2003). Silencios y susurros: la cuestión de la anticoncepción y el aborto. Revista Jurídica Universidad Interamericana de Puerto Rico, Puerto Rico.

Gusfield, J. (2014). La cultura de los problemas públicos. Buenos Aires: Siglo XXI.

Habermas, J. (1999). Teoría de la acción comunicativa: racionalidad de la acción (vol. I) Madrid: Taurus.

Hine, C. (2004). Etnografía virtual. Barcelona: Edit. UOC.

Honneth, A. (1981). Conciencia moral y dominio social de clases. Algunas dificultades en el análisis de los potenciales normativos de la acción. En La sociedad del desprecio (pp. 55-73). Madris, España: Trotta editorial.

Honneth, A. (1992). Integridad y desprecio. Revista Isegoría, 5, pp. 78-92.

Honneth, A. (1997). La lucha por el reconocimiento. Barcelona, España: Crítica.

Honneth, A. (2009a). Crítica del poder. Madrid, España: Machado Libros. 
Honneth, A. (2009b). Desarrollo moral y lucha social. En Crítica del agravio moral (pp. 197224). España: Fondo de Cultura Económica.

López, G. y Ciuffoli, C. (2012). Facebook es el mensaje. Oralidad, escritura y después. Buenos Aires, Argentina: La Crujía Ediciones.

Perelman, C. y Olbrechts Tyteca, L. (1958). Tratado de la argumentación: la nueva retórica. Madrid: Gredos.

Petracci, M. (abril de 2007). Opinión pública sobre interrupción voluntaria del embarazo y despenalización del aborto en la Argentina y América Latina. Despenalización.org.ar, 01. Recuperado de http://www.cedes.org/publicaciones/documentos/HI/6053.pdf

Robrieux, J. J. (1993). Eléments de Rhétorique et d'Argumentation. París: Dunod.

Rocha, M. I.; Rostagnol, S. y Gutiérrez, M. A. (2008). Aborto y parlamento: un estudio comparativo sobre Brasil, Uruguay y Argentina. Trabajo presentado en el III Congreso de la Asociación Latinoamericana de Población, Córdoba, Argentina.

Zamberlin, N. (2007). El aborto en la Argentina. Despenalización.org.ar, 03. Recuperado de http://www.cedes.org/publicaciones/documentos/HI/6061.pdf

\section{Fuentes consultadas}

Intrusos en el espectáculo (2 de febrero de 2018). Discurso de apertura de Jorge Rial. Recuperado de https://www.youtube.com/watch?v=3cPhcgkLdtw Intrusos en el espectáculo (2 de febrero de 2018). Polémica, Jorge Rial quiere abrir el debate por el tema del aborto legal en la TV. Recuperado de https://www.youtube.com/watch?v=r85iXBakCPY

Intrusos en el espectáculo (5 de febrero de 2018). Participación de Virginia Godoy. Recuperado de https://www.youtube.com/watch?v=QHPsXkZC8Lc 